\title{
Investigations of nanostructured three-phase-foams and their application in foam concretes - a summary
}

\author{
Christina Krämer, Reinhard H. F. Trettin \\ Department Chemistry and Biology, Institute for Building and Materials Chemistry, University of Siegen, \\ Paul-Bonatz-Str. 9-11, Siegen, 57076, Germany
}

"Corresponding author: Tel: (+49) 2717402123; E-mail: kraemer@chemie.uni-siegen.de

Received: 08 November 2016, Revised: 29 November 2016 and Accepted: 13 December 2016

DOI: $10.5185 /$ amlett.2017.1593

www.vbripress.com/aml

\begin{abstract}
Recently, a new approach was developed and published which focuses on the preparation of inorganic foams and their application in foam concrete production. Through the incorporation of nanostructured pozzolans in the foam structure, socalled three-phase-foams show a higher stability than foams only based on surfactants. Due to pozzolanic hardening, shrinkage cracks were healed and reaction products can be observed. By implementation of nanotubes in the foam structure as nanoreinforcement, a further stabilization was reached. After incorporation of wet three-phase-foams in cement paste, foam concretes with improved mechanical properties were achieved. It was also shown that the pore size distribution was similar to the introduced three-phase-foams and also smaller pore sizes can be observed compared to foam concretes based on surfactant foams. Additionally, a specific shell-like pore structure was obtained and a theoretical model developed. This could be confirmed by investigations of the influence of the surfactant used on the formation and carbonation of calcium hydroxide. To further enhance the mechanical properties of foam concretes based on three-phase-foams, an UHPC (Ultra-high Performance Concrete) formulation has been applied. Resultant UHPC foam concretes showed dense packed borders, improved homogeneity related to the pore size distribution and enhanced mechanical properties. Furthermore, the UHPC approach was combined with nanoreinforcement. Copyright @ 2017 VBRI Press.
\end{abstract}

Keywords: Three-phase-foams, foam concrete, nanotubes, nanoparticles, lightweight materials.

\section{Introduction}

The importance of lightweight materials is related to their advantageously economical and physical properties. Lightweight constructions enable cost by materials savings, noise insulation, low thermal conductivity as well as load-bearing capacity and can be applied in different areas. Beside the use of metals in automotive industry and polymers for thermal insulation of buildings, for example, also inorganic binders offer various possibilities to produce lightweight materials $[\mathbf{1}, \mathbf{2}]$. In case of cementitious binders, especially lightweight concretes are of great interest. On the one hand, voids are created by using natural or lightweight aggregates [3]. On the other hand, generation of voids can be reached by inclusion or stabilization of air pores inside the binder paste. Therefore, densities of below $2000 \mathrm{~kg} / \mathrm{m}^{3}$ down to $150 \mathrm{~kg} / \mathrm{m}^{3}$ can be achieved $[4,5,6]$. Hereby, two different types of lightweight concretes are well-known. Aerated concrete is produced chemically by using aluminum powder, for example, which generates voids due to the formation of hydrogen. Also other reactions which enable gas formation after reaction are used. Afterwards, generally autoclaving process follows for strengthening [7]. Foam concrete is based on mechanical or physical-mechanical foaming. For the former, foaming agent is added in the mixing water and air pores are formed during stirring the paste. The latter is achieved by mixing a pre-prepared wet-foam based on proteins or surfactants with the binder paste [8]. A comparison of foam concrete with aerated concrete shows, that there are advantages regarding cost savings, sustainability and environmental compatibility.

However, issues are to reach high strength with less material and thin borders as well as a controlled and homogeneous air entry. This is enabled on the basis of a dense packing of the starting materials within the borders. To improve especially mechanical properties without any further curing, Schauerte et al. developed foam concretes based on an Ultra-high Performance Concrete (UHPC) formulation and surfactant foams (two-phase-foams) [9]. Reduced W/C ratios, use of reactive supplements and optimized packing density following the model of Funk and Dinger are applied, to reach densely packed borders with UHPC performance [10-12]. UHPC foam concretes with comparable strength and thermal insulation like autoclaved concrete but without using energy consuming autoclave treatment were enabled. Also, improved thermal insulation properties and compressive strength in combination resulted [9]. Furthermore, those UHPC foam concretes were combined with carbon nanotubes/fibers (CNTs/CNFs) and led to enhanced mechanical properties, 
especially improved compressive strength [13]. Beside significantly improved mechanical performance, influences of CNTs on the pore structure, formation of calcium hydroxide and calcium-silicate-hydrate $(\mathrm{C}-\mathrm{S}-\mathrm{H})$ phases and decreased thermal conductivity were reported [14-18].

A new way to further improve the properties of foam concrete is the initial entry of foams consisting of a third solid phase (three-phase-foams). Following Gonzenbach et al. in-situ hydrophobation and adsorption of particles at the gas-liquid (disperse-continuous) interface can be ensured by electrostatic forces between the particles and surfaceactive agents, which lead to a sorption on the particle surface. Those partially hydrophobized particles introduced in the gas-liquid interface result in high foam stability [19]. High-volume particle stabilized foams were prepared based on short-chain amphiphiles and used to produce macroporous ceramics [20] but also the development and characterization of polymer and metal foams as well as capsules from ceramics based on this new foaming technique are focused.

To adapt this approach to cementitious binders, surfactants need to be compatible to not only the binder but also to used solid or nanoparticles, respectively, to prepare three-phase-foams. Furthermore, usually lower solid content but still high foam stability, in particular at the beginning and during mixing is necessary. Additionally, resulted three-phase-foams have also to be stable in the presence of further organic additives which control rheology of the binder paste, for example. Eventually, the recipe has to be adapted in such a way that a homogeneous entry without agglomeration or sedimentation takes place.

Finally, preparation of foam concrete based on threephase-foams was successfully done. Nanosilica used generates an additional increase in strength and stabilization in foam concrete. It was shown that the air pores of resulting foam concretes were similar to the entered foams and had a characteristic pore structure with respect to the formed hydration products. The produced foam concretes were comparable to industrial lightweight concretes and had even partially improved mechanical properties [1].

Further improvements were reached by introducing CNTs in three-phase-foams and implement those foams in foam concrete. Although the resulting foam concretes have to be optimized, a higher compressive strength compared to foam concretes based on three-phase-foams without CNTs and industrial foam concretes was reached even after $7 \mathrm{~d}[\mathbf{1 3}, \mathbf{2 1}]$.

To further enhance especially mechanical properties of foam concretes based on three-phase-foams, UHPC approach was applied. Hereby, in a first step water/cementratio (W/C-ratio) from previously 0.5 was decreased to 0.25 . Microstructural investigations and results of phase development showed improvements compared to foam concretes without three-phase-foams and also preliminary results. Narrower pore size distribution, smaller pore sizes and lower calcite contents were observed which showed a more homogeneous and more closed pore structure as well as higher packing of the concrete matrix. A higher hydration degree due to three-phase-foams in UHPC foam concretes caused by pozzolanic reaction and seeding of nanosilica used was observed. Also, a shell-like pore structure which was observed in previous investigation [1] can be found in UHPC foam concretes. First results showed that the compressive and flexural strength is even more positively affected due to the combination of three-phasefoams and UHPC formulation [22]. Thus, not only a strengthening was enabled but also a controlled and homogeneous air entry obtained which resulted in a stable homogeneous pore structure. Beside the low W/C-ratio and use of reactive supplements, an optimized packing or minimum porosity of the dry mix is crucial for UHPC formulations and enable durability and strengthening of the concrete matrix [9]. Following Schauerte et al. optimized packing density was additionally applied on previous UHPC foam concretes based on three-phase-foams as shown in [22] and $50 \% \mathrm{w} / \mathrm{w}$ cement substituted by aggregates. Furthermore, those were combined with nanotubes as nanoreinforcement. The incorporation of three-phase-foams with and without nanotubes was successfully done and improved mechanical properties achieved [23].

Another approach to produce inorganic foams with densities less than $150 \mathrm{~kg} / \mathrm{m}^{3}$ is based on a pozzolanic hardening in calcium hydroxide solutions [24]. Hereby, thermal treatment was initially not applied. These pozzolanic hardened foams can also be combined with different nanotubes which can enable and transfer various properties $[\mathbf{2 5 , 2 6}]$. Finally, it was figured out that the surfactant and nanotubes used had an influence on pozzolanic reaction and formation of reaction products, especially on the morphology and carbonation of portlandite. Based on these studies a previously developed model of the pore structure could be verified, as well as first indications for the sorption of the surfactant obtained [23,27].

This paper gives an overview about the author's recent research of the investigations of three-phase-foams and their application in foam concrete. It was shown that those can improve the microstructure and mechanical properties of foam concrete. Furthermore, three-phase-foams can also be combined with UHPC formulation which improves even more the performance of resulting UHPC foam concrete references. The ability to implement nanotubes in the foam structure could enable nanoreinforcement and transferring specific properties to three-phase-foams for foam concrete production or the use of those as a selfcontained materials after pozzolanic hardening and further optimization.

The primary objectives of this work regarding threephase-foams are the preparation of inorganic foams based on the direct foaming method following Gonzenbach et al. and applying nanoreinforcement. In these studies, a longchain surfactant is investigated in the three-phase-system due to its low cost, easy handling, environmental compatibility and possibility to be further introduced in other binders although lower foam stability is reached compared to certain short-chain amphiphiles. The problem of crack formation during drying process should be solved 
and strengthening enabled with a chemical treatment (pozzolanic hardening) which will be shown in the following chapters. Implemented nanotubes could not only enable nanoreinforcement but also seeding for reaction products to improve the resultant foam microstructure and performance. Regarding three-phase-foams in cementitious binder, suitability and adaption of those for the application in foam concrete and UHPC foam concrete are focused. The successful introduction of three-phasefoams with and without nanotubes in foam concrete could lead to an enhanced pore structure and bulk matrix through providing higher foam stability during stirring and formation of as well as influence on reaction products (i.e. pozzolanic reaction, seeding etc.). Moreover, an optimized integration of nanomaterials in the binder matrix could be enabled

Three-phase-foams provide many possibilities for the combination with other surface active agents and binders to improve the performance of lightweight materials and adapt certain requirements for different applications. were produced simultaneously and afterwards the foam was mixed in the binder paste. Rheology was adjusted with superplasticizer and stabilizer in case of using aggregates. Packing optimized UHPC foam concrete was based on quartz sand / flour whereby $50 \%$ w/w cement was replaced by aggregates.

\section{Diffusion / precipitation synthesis of calcium hydroxide}

Diffusion synthesis of $\mathrm{Ca}(\mathrm{OH})_{2}(\mathrm{CH})$ was done by using $\mathrm{KOH}$ and $\mathrm{CaCl}_{2}$ (Sigma Aldrich and Merck) in a molar ratio of $2: 1$. Solid materials were added in glass tubes whereby a smaller glass tube was put in a bigger one and both filled with deionized, degassed water or surfactant solutions with different concentrations, respectively, so that a diffusion process took place. For the formation of $\mathrm{CH}$ by the means of precipitation synthesis, $\mathrm{KOH}$ (1 molar) and $\mathrm{CaCl}_{2}$ (0.1 molar) solutions were prepared. Subsequently, $20 \mathrm{~mL}$ of $\mathrm{CaCl}_{2}$ was added dropwise in $100 \mathrm{~mL} \mathrm{KOH}$ in argon flow. Different surfactant concentrations were used and dropping as well as stirring rate were kept equal [27].

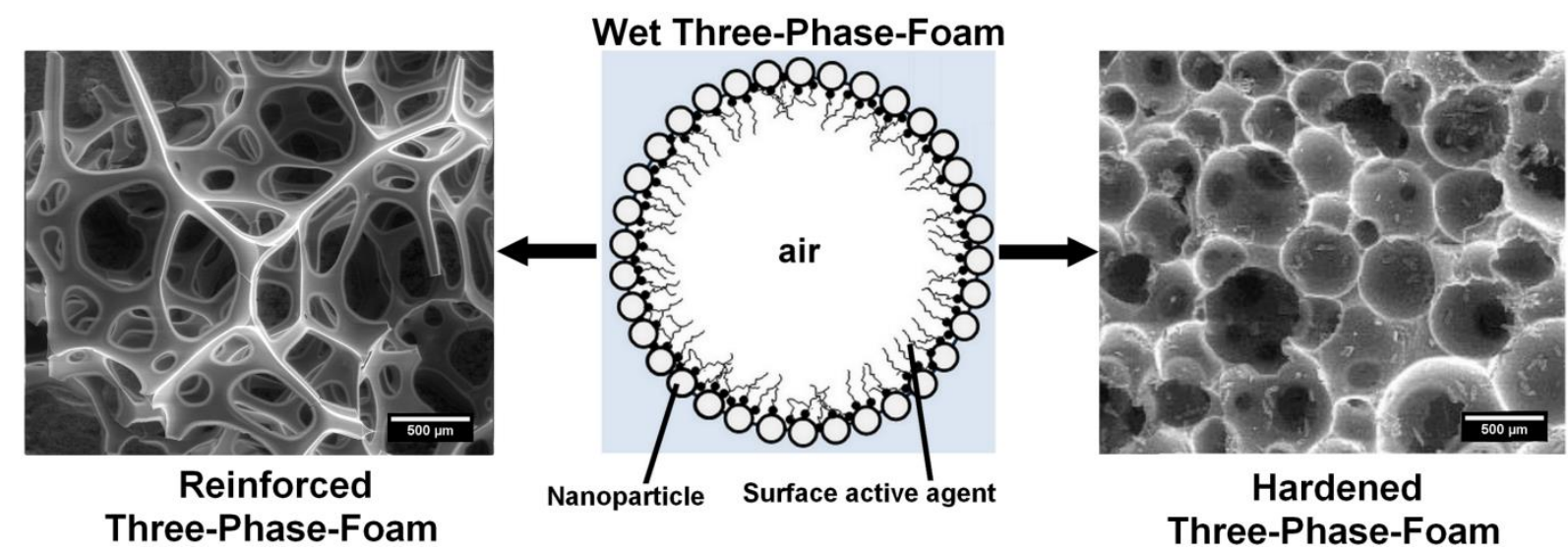

Fig. 1. Schematic representation of wet three-phase-foam (middle); SEM images after nanoreinforcement with nanotubes (left) and pozzolanic hardening in calcium hydroxide solution (right) both after drying, scale bar $500 \mu \mathrm{m}$.

\section{Experimental}

\section{Preparation of three-phase-foams}

Cocamidopropyl betaine (TEGO Betain F50, Evonik) was used as the surfactant and AEROSIL® 90 as well as MOX 80 (both Evonik) as the solid phase [24] in three-phasefoams (TPF). Water-based dispersion was prepared by adding nanoparticles in deionized water, maintenance of $\mathrm{pH}$ at absolute maximum of zeta potential and using ultrasound. For nanoreinforcement oxidized / $\mathrm{SiO}_{2}$-coated carbon nanotubes (oxCNTs / coatCNTs) and titanate $\left(\mathrm{TiO}_{2}\right.$ based) nanotubes (TiNTs) were introduced during dispersion process with appropriate amount of surfactant as dispersing agent $[\mathbf{2 5 , 2 6 ]}$. After adding surfactant used, homogenizing and foaming was done simultaneously.

\section{Preparation of foam concretes and UHPC foam concretes}

Preparation of foam concrete was done by using W/Cratios of $0.5[\mathbf{1 , 1 3 , 2 1}]$ and $\leq 0.27$ for UHPC foam concretes $[\mathbf{2 2 , 2 3}]$. Cement / Mortar paste and three-phase-foams

\section{Results and discussion}

\section{Investigations on nanostructured three-phase-foams}

Three-phase-foams used were based on $\mathrm{SiO}_{2}$ nanoparticles or nanosilica (NS), respectively, but also a mixed oxide (MO) with $99 \% \mathrm{SiO}_{2}$ and $1 \% \mathrm{Al}_{2} \mathrm{O}_{3}$ used. N-hexylamine $(\mathrm{HA})(\mathrm{pKa}=10.56)$ and cocamidopropyl betaine $(\mathrm{B})(\mathrm{pKa}$ $<5.5 ; \mathrm{CMC}=0.08 \mathrm{mmol} / \mathrm{L}$ ) were used as surface active agents. Electrostatic interaction between surface active agents and particle surfaces was enabled due to the amino function and a deprotonated particle surface at $\mathrm{pH} 10$ (absolute maximum of zeta potential). Nanoparticle dispersion was prepared and surfactant added. Then homogenizing and stirring was done simultaneously with a dynamic stirrer.

In case of reinforced three-phase-foam (Fig. 1, left), nanotubes were added and treated in the dispersion prior foaming. After preparation, pore size distribution and foam stability as well as further microstructural properties were determined. For pozzolanic hardening inorganic foams 
Table 1. Overview of microstructural properties, densities and foam stabilities of different three-phase-foams shown in [24-26].

\begin{tabular}{|c|c|c|c|c|c|c|c|c|}
\hline \multirow{2}{*}{ Lit } & \multirow{2}{*}{ Samples } & \multirow{2}{*}{$\begin{array}{l}\text { Por e radii } \\
\qquad(\mu \mathrm{m})\end{array}$} & \multirow{2}{*}{$\begin{array}{c}\text { Por e radii } \\
\leq 150 \mu \mathrm{m}(\%)\end{array}$} & \multirow{2}{*}{$\begin{array}{l}\text { border width } \\
(\mu \mathrm{m})\end{array}$} & \multirow{2}{*}{$\begin{array}{l}\text { lamellae width } \\
(\mu \mathrm{m})\end{array}$} & \multicolumn{2}{|c|}{${ }^{*}$ Loss of continuous phase (\%) } & \multirow{2}{*}{$\begin{array}{c}{ }^{*} \text { Densities } \\
\left(\mathrm{kg} / \mathrm{m}^{3}\right)\end{array}$} \\
\hline & & & & & & $t=10 \min$ & $t=60 \min$ & \\
\hline \multirow{6}{*}[24]{} & NS & $50-500$ & 32 & $25-400$ & $\sim 1.0$ & 1 & 50 & 120 \\
\hline & $\mathrm{NS}_{\text {hardened }}$ & $50-650$ & 25 & $150-400$ & $1.0-2.0$ & - & - & - \\
\hline & $\mathrm{MO}$ & $30-500$ & 69 & $30-150$ & $\sim 1.0$ & 4 & 80 & 120 \\
\hline & ${ }^{* * *}$ NS_HA & $50-400$ & 71 & $25-300$ & $\sim 2.0$ & 0 & 0 & 270 \\
\hline & ${ }^{* *} \mathrm{NS}_{-} \mathrm{H} \mathrm{A}_{\text {hardened }}$ & $50-400$ & 83 & $25-300$ & $\sim 2.0$ & - & - & - \\
\hline & NS_oxCNTs & $50-650$ & 42 & $100-200$ & $0.5-1.0$ & 0 & 0 & 90 \\
\hline \multirow[t]{3}{*}[25]{} & NS_oxCNTs sardened & - & - & $25-300$ & $1.0-1.5$ & - & - & - \\
\hline & MO_oxCNTs & $30-600$ & 33 & $100-250$ & $0.5-1.0$ & 5 & 75 & 60 \\
\hline & & & $\begin{array}{c}\text { Pore radii } \\
\leq 20 \mu \mathrm{m}(\%)\end{array}$ & & & & & \\
\hline \multirow{9}{*}[26]{$^{* * * *}$} & NS & $10-80$ & 64 & $50-100$ & $\sim 1.0$ & 0 & 0 & 60 \\
\hline & $\mathrm{NS}_{\text {_hardened }}$ & - & - & $50-150$ & $1.0-1.5$ & - & - & \\
\hline & NS_oxCNTs & $10-80$ & 62 & $50-150$ & $0.5-1.0$ & 4 & 33 & 80 \\
\hline & NS_oxCNTs $s_{\text {hardened }}$ & - & - & $50-200$ & $0.5-1.5$ & - & - & \\
\hline & NS_coatCNTs & $10-90$ & 64 & $100-250$ & $1.0-1.5$ & 0 & 0 & 90 \\
\hline & NS_coatCNTs $s_{\text {hardened }}$ & - & - & $100-300$ & $1.5-2.5$ & - & - & \\
\hline & NS_TiNTs & $10-90$ & 58 & $100-250$ & $0.5-1.5$ & 0 & 20 & 75 \\
\hline & ${\mathrm{NS} \_T i N T s_{\text {hardened }}}$ & - & - & $100-300$ & $1.0-2.0$ & - & - & - \\
\hline & $\begin{array}{l}* \text { related to most stable } \mathrm{f} \\
* * \mathrm{HA}=\text { Hexylamine } \\
* * * \text { improved foaming } \mathrm{p}\end{array}$ & & & & & & & \\
\hline
\end{tabular}

without and with nanotubes were stored in calcium hydroxide solution for $7 \mathrm{~d}$. Investigations on the microstructure and phase composition were carried out after drying (Fig.1, right). A schematic representation of a wet three-phase-foam is given in (Fig.1, middle). It should be mentioned that the schematic presentation of wet threephase-foams in Fig. $\mathbf{1}$ and similar schemes shown in $[\mathbf{1 , 2 4 , 2 5}]$ do not include all the sorption behavior of surfactants (e.g. at the gas-liquid-interface and on the particle surfaces (located at the interface and in the bulk) and particle-particle interaction after sorption of surfactants (e.g. van der Waals forces and hydrophobic attractive forces) etc. in the continuous phase for simplification. Eventually, to clarify the different adsorption mechanisms and interactions which occur in the wet three-phase-foams using betaine with and without nanotubes and to examine their contribution to the properties of the inorganic foams, e.g. influencing foam stability (rheology, formation of a solid network, entanglement / interlocking, interfacial elasticity, steric hindrance etc.), further studies have to be done. Since those investigations were not focused, the authors refer to the literature for more insights.

Table 1 gives an overview of the most stable threephase-foams of the different studies done, regarding microstructure, densities and foam stability over time [2426]. Here, pore sizes were determined by light microscopy (LM) followed by statistical frequency analysis. Loss of continuous phase is equal to $\% \mathrm{w} / \mathrm{w}$ of the drained liquid phase over time related to the total foam weight.

\section{Pozzolanic hardened three-phase-foams}

It was shown that most stable foams were prepared by using $35 \%$ w/w NS with $75 \mathrm{mmol} / \mathrm{L} \mathrm{HA}$ or $60 \mathrm{mmol} / \mathrm{L} \mathrm{B}$, respectively, and $30 \% \mathrm{w} / \mathrm{w} \mathrm{MO}$ with $10 \mathrm{mmol} / \mathrm{L} \mathrm{B}$. HA provided the highest stability with no loss of continuous phase, narrow pore size distribution and high amount of small pore radii below $150 \mu \mathrm{m}$ but high density and thickest borders / lamellae widths. After hardening the percentage of pores at a certain size changed which could be explained by both reductions of smaller pores, especially in the range of $60 \mu \mathrm{m}$ and pore radii in the range of 200-250 $\mu \mathrm{m}$ due to the formation of reaction products. For three-phase-foams based on B loss of continuous phase took place but foam stability compared to surfactant foam (two-phase-foam) was improved, in particular in the beginning up to $20 \mathrm{~min}$. After hardening of NS B, lamellae / border widths increased and also shrinkage cracks were healed determined by scanning electron microscopy (SEM). For MO no hardening was possible.

Beside the lower stability and densities by using B compared to HA, also an influence on the crystallinity of $\mathrm{C}-\mathrm{S}-\mathrm{H}$ was determined. At lower concentrations of B intensities of semi-crystalline $\mathrm{C}-\mathrm{S}$ - $\mathrm{H}$ phases were seen in XRD whereby at higher surfactant concentration no C-S-H can be found in X-ray diffraction (XRD). Element mapping by energy dispersive X-ray spectroscopy (EDX) showed a homogeneous distribution of calcium over the whole structure so that formation of reaction products is enabled. By simultaneous thermal analysis (STA) water loss took place over a wide range above $100^{\circ} \mathrm{C}$. After hardening process almost all foams showed a denser microstructure or packing in the borders / lamellae observed in SEM. 
Thus, the formation of reaction products such as C-S-H phases, calcium hydroxide and calcium carbonate caused by the pozzolanic reaction, crystallization and carbonation, respectively, occurred [24].

\section{CNT-stabilized three-phase-foams}

By implementation of oxidized CNTs, foams based on MO B were slightly stabilized using $0.3 \% \mathrm{w} / \mathrm{w}$ CNTs related to the nanoparticle content. In case of NS B amounts of 0.5$1.0 \% \mathrm{w} / \mathrm{w}$ CNTs led to an absolute stabilization without any drain in 60 min. Compared to NS B and MO B without $\mathrm{CNTs}$, pore radii distributions were broadened and a higher content of pores below $150 \mu \mathrm{m}$ for NS B with CNTs and a lower content for MO B with CNTs were observed. Also lower densities of $0.09 \mathrm{~g} / \mathrm{cm}^{3}$ for NS B and $0.06 \mathrm{~g} / \mathrm{cm}^{3}$ for MO B even immediately after foam production and smaller border and lamellae widths were observed by incorporation of CNTs.

For CNT-stabilized foams after hardening, denser structure or packing in the borders / lamellae were observed by SEM. This means that the formation of reaction products took place, which was also shown in the study of phase development. Thus, the interactions between surfactant, particle surface and other additives as well as steric effects were concluded as additional important factors for high foam stability [25].

\section{Reinforced and hardened three-phase-foams}

In a further step, various nanotubes were implemented and their influences investigated. In addition to oxidized CNTs, $\mathrm{SiO}_{2}$-coated CNTs (sol-gel method with oxidized CNTs) and titanate nanotubes (TiNTs; modified hydrothermal synthesis with anatase and $\mathrm{NaOH}$ ) were prepared and applied. Additionally, foaming parameter was adapted [26]. In case of oxidized CNTs foam stability was decreased compared to previous investigations. This can be explained by less surfactant amount due the use of only $20 \mathrm{mmol} / \mathrm{L} \mathrm{B}$ instead of $60 \mathrm{mmol} / \mathrm{L}$. Resulting foams showed narrow pore sizes with pore radii between 10 and $90 \mu \mathrm{m}$ whereby around $60 \%$ were smaller than $20 \mu \mathrm{m}$. The final step of adapting the surfactant concentration (for dispersing and foaming) to each combination used could result in an absolute stable foam system even by using long-chain surfactants.

Border / lamellae widths of three-phase-foams with TiNTs and coatCNTs were larger and pore size distribution more inhomogeneous than without nanotubes and with oxCNTs (Fig. 2). Lamellae / border widths were increased and strengthening reaction products like $\mathrm{C}-\mathrm{S}-\mathrm{H}$ phases or calcium carbonate $(\mathrm{Cc})$ were built, respectively, due to pozzolanic hardening and carbonation.

Additionally, influences of additives used on pozzolanic reactivity were investigated. Hereby, C-S-H phases were formed in almost every sample but are strongly influenced by the surfactant. It was also assumed that the surfactant betaine formed hydrotalcite-like structures in calcium hydroxide solution probably promoted in the presence of $\mathrm{CO}_{2}$ but has to be investigated in more detail. Betaine had also a great influence on the morphology and particle sizes of calcium hydroxide and carbonate. In addition, it was obtained that TiNTs have a high calcium affinity and were good seeds for calcium containing reaction products. It was also observed that oxCNTs tend to adsorb betaine molecules.

Thus, the formation of reaction products and foam stability is mainly referred to the surfactant used which provides high sorption ability on both nanomaterials and reaction products [26].

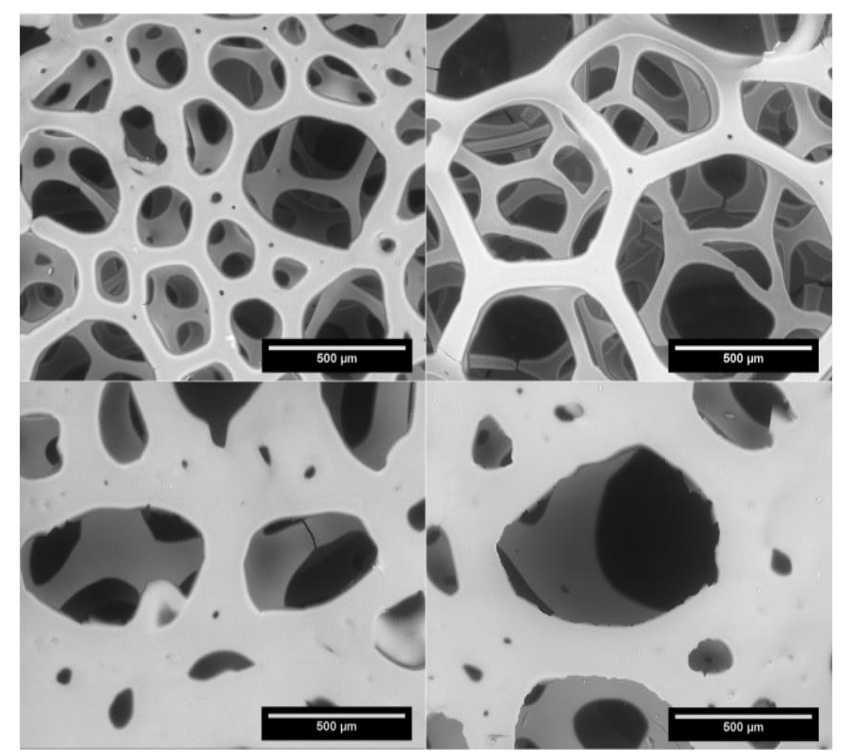

Fig. 2. SEM images of dry three-phase-foams without nanotubes (upper left), with oxCNTs (upper right), coatCNTs (lower left) and TiNTs (lower right).

\section{Three-phase-foams in foam concrete application}

The advantage of higher foam stability of three-phasefoams compared to surfactant foams and also the usage of pozzolans as a third phase which could enable a strengthening of the borders by reaction with $\mathrm{CH}$ formed during the cement hydration, are promising to improve the performance of foam concrete. Hereby, it is mostly important to not only provide compatibility between surfactants and cementitious binders but also required stability in presence of further additives should be given. Regarding cost savings and workability in especially UHPC formulation, lower nanoparticle contents are used for three-phase-foams. Beside the fact that low application quantities of nanomaterials even less than $1 \% \mathrm{w} / \mathrm{w}$ are absolutely effective, still high foam stability particularly in the beginning is essential. Finally, an adjustment of the recipe has to be done in such a way that a homogeneous entry without agglomeration or sedimentation is enabled.

\section{Foam concretes}

In a first step three-phase-foams were applied with a higher NS content of $2 \% \mathrm{w} / \mathrm{w}$ related to the cement content in cement paste and their improvement successfully proven. These foam concretes provide higher compressive strength than industrial foam concrete without further optimization or using UHPC formulation. It was also shown that the pore size distribution of the used three-phase-foams and resulting foam concretes were in a similar value. In 
addition, a thin layer of $\mathrm{CH}$ crystals which may have grown together on the inner pore surface and C-S-H-rich areas on the exterior surface were observed. Also, different particle sizes of $\mathrm{CH}$ and $\mathrm{Cc}$ were examined in STA which was assumed to be influenced by the surfactant used. The sum of formed $\mathrm{CH}$ and $\mathrm{Cc}$ was lower in XRD and thus certain amounts were X-ray amorphous. The findings of different particle sizes and X-ray amorphous content could be referred to very small particles which could be assumed to be grown together in the $\mathrm{CH}$ layer [1].

The shell-like pore structure was assumed to be based on the maintenance of the electrostatically adsorbed surfactants on the particles (Fig. 3). Hereby, the pozzolanic reaction could take place mainly surface-near in the pore exterior surface and is also assumed to be influenced by the surfactant regarding especially crystallinity. The portlandite layer is caused by the surfactants nearby and in the pore solution.

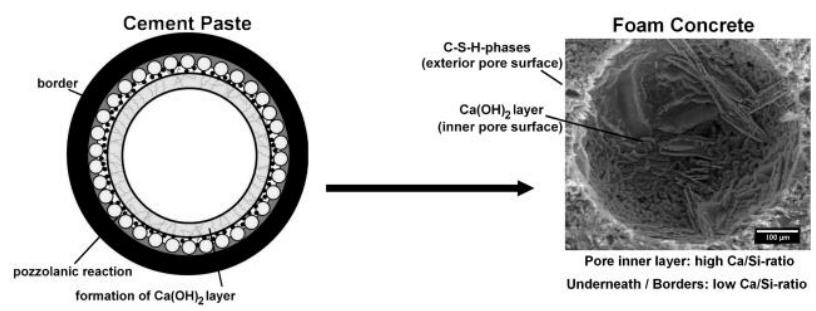

Fig. 3. Theoretical model of the cement paste after incorporation of threephase-foams (left) and resulting pore structure after hydration (right).

\section{CNT-stabilized foam concretes}

In a next step CNT-stabilized three-phase-foams were used for preparation of foam concrete whereby NS content was still $2 \% \mathrm{w} / \mathrm{w}$ and CNT content $0.01 \% \mathrm{w} / \mathrm{w}$ related to the cement content. Due to this, a higher compressive strength compared to industrial foam concretes was reached even after $7 \mathrm{~d}$ and improved compared to foam concrete without CNTs by $30 \%$ after $28 \mathrm{~d}$. Also, a shell-like pore structure as well as similar pore sizes values of the introduced foam and resulting foam concrete were observed $[\mathbf{1 3}, \mathbf{2 1}]$.

\section{UHPC foam concretes}

To further improve the microstructure of foam concrete, enhance certain properties like strength and decrease transport of heat and moisture, $\mathrm{W} / \mathrm{C}$ ratio was reduced. The amount of nanoparticles was $0.6 \% \mathrm{w} / \mathrm{w}$ related to the cement content to provide a good workability without agglomeration. Compared to the reference without threephase-foams but also to preliminary results, microstructural properties and their phase composition were improved. As assumed, resulting UHPC foam concretes with lower W/C ratios showed denser borders compared to foam concretes with higher W/C-ratios (Fig.4, upper left and right). Also, pore sizes were smaller and more homogeneous observed by SEM (Fig. 4, lower left and right) $[22]$.

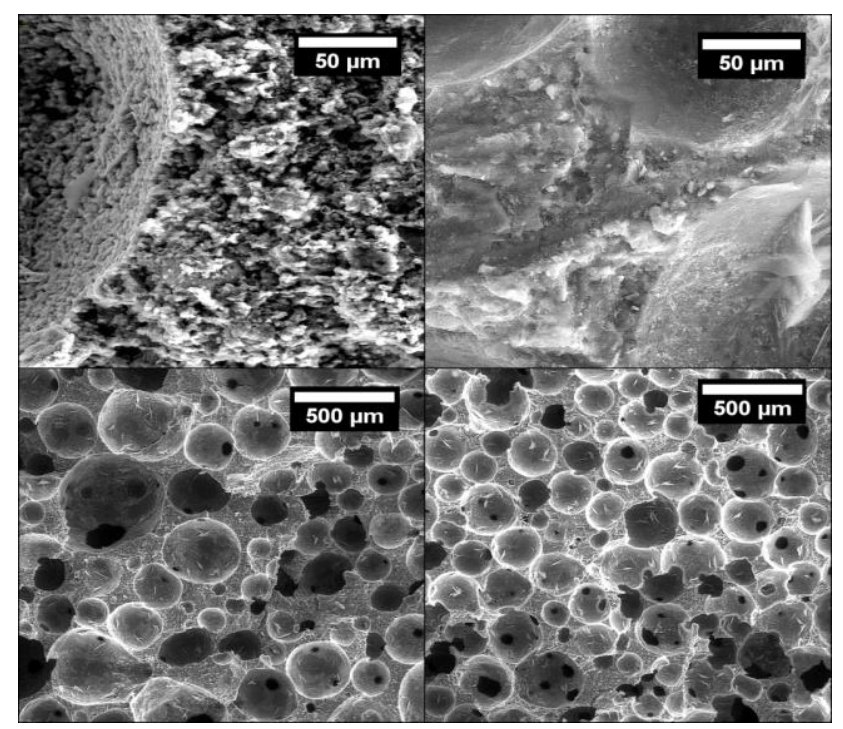

Fig. 4. SEM images of borders in foam concrete based on $\mathrm{W} / \mathrm{C}=0.5$ (upper left) and 0.25 (upper right) and cross sections of foam concretes with W/C 0.25 based on two-phase (lower left) and three-phase-foam (lower right) after $28 \mathrm{~d}$.

Examined pore structure by LM showed smaller pore sizes and a narrower pore size distribution compared to previous results and to the reference (Table 2) $[\mathbf{1 , 2 2}]$. Investigations of the phase composition with XRD resulted in lower calcite content of $1 \% \mathrm{w} / \mathrm{w}$ (previously $4-5 \% \mathrm{w} / \mathrm{w}$ ) and by EDX less carbon in surface-near regions was detected. Compared to previous investigations, a high packing and a more closed pore structure could be confirmed. Also, a higher hydration degree was shown and thus a pozzolanic reaction of the introduced nanosilica

Table 2. Oven-dry densities and pore sizes of the different foam concretes based on three-phase-foams after $28 \mathrm{~d}$.

\begin{tabular}{|c|c|c|c|c|c|}
\hline Lit & Samples & $\begin{array}{c}\text { Oven-dry density } \\
\left(\mathrm{kg} / \mathrm{m}^{3}\right)\end{array}$ & $\begin{array}{l}\text { Pore radii } \\
\qquad(\mu \mathrm{m})\end{array}$ & $\begin{array}{c}\text { Pore radii } \\
\leq 150 \mu \mathrm{m}(\%)\end{array}$ & $\begin{array}{c}\text { Average pore radii } \\
\qquad(\mu \mathrm{m})\end{array}$ \\
\hline [1] & Foam concrete & \multirow{3}{*}{$1070 \pm 10$} & $40-660$ & 31 & 230 \\
\hline [22] & UHPC foam concrete & & $30-600$ & 74 & 120 \\
\hline \multirow{3}{*}{ [23] } & $\mathrm{UHPC}_{\text {foam concrete }} \mathrm{TPF}$ & & $30-500$ & 80 & 100 \\
\hline & UHPC foam concrete & \multirow{2}{*}{$1250 \pm 30$} & $160-750$ & 60 & 160 \\
\hline & UHPC foam concrete ${ }_{\mathrm{TPF}}$ & & $160-780$ & 60 & 160 \\
\hline
\end{tabular}

* $50 \% \mathrm{w} / \mathrm{w}$ cement replacement (packing optimized) 
could be inferred. Additionally, previously shown shelllike pore structure was observed. Finally, mechanical properties are positively affected (Fig. 5).

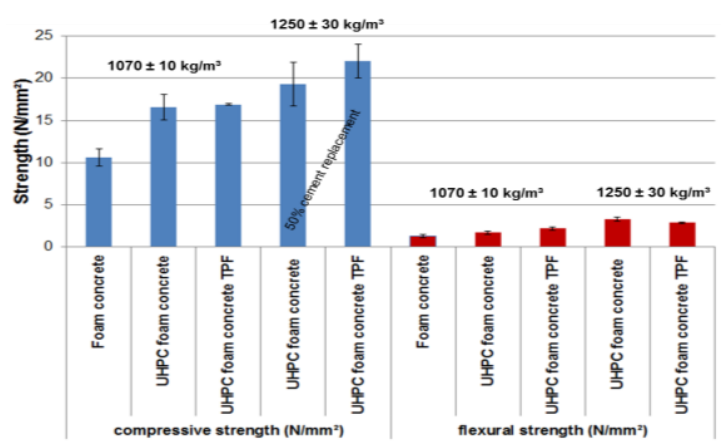

Fig. 5. Mechanical properties of the different foam concretes and UHPC foam concretes after $28 \mathrm{~d}$.

Application of reinforced three-phase-foams in UHPC foam concretes

Furthermore, UHPC foam concretes were prepared by substitution of $50 \% \mathrm{w} / \mathrm{w}$ cement with quartz aggregates based on packing optimization following the model of Funk and Dinger. By comparing examined pore sizes in Table 2, it can be seen that those of the reference and based on TPF are similar but still improved compared to normal concrete application [1,23]. Especially, enhanced mechanical properties can be reached (Fig. 5) in particular after $16 \mathrm{~h}$ [23].

In addition, titanate and oxidized carbon nanotubestabilized TPF were successfully implemented but further optimization has to be made by adaption of foam stability related to the amount of nanotubes and surfactant. Both nanotubes showed a seeding effect and differences in formed hydration products, particularly C-S-H. Hereby, TiNTs were assumed to provide seeding for C-S-H which can be especially seen in the early stage of hydration. Furthermore, investigations in saturated $\mathrm{CH}$ solution was carried out as a model system whereby pozzolanic reactivity and calcium ion sorption ability were focused $[\mathbf{2 3}, \mathbf{2 6}]$. However, it must be considered that the results point out first insights into a very complex system in which several aspects have been taken into account (i.e. carbonation etc.). Thus, values should be considered as relative parameters for first indications. TiNTs showed a high calcium affinity and were good seeds for calcium containing reaction products. These were less affected by the surfactant used but in case of CNTs, surfactant molecules were probably sorbed on the nanotube surface. Mainly due to the surfactant, reaction products $\mathrm{CH}$ and $\mathrm{Cc}$ were partially X-ray amorphous, showed smaller particle sizes and change in morphology. Hereby, the formation of smaller particles could be advantageous so that the microstructure is less affected by larger crystal formation, for example, leading to a better performance. Freely available surfactant molecules in solution phase also influence carbonation of $\mathrm{CH}$. It was shown that the surfactant chelates / adsorb calcium ions, led to $\mathrm{CH}$ precipitation and could form hydrotalcite-like reaction products probably promoted in the presence of $\mathrm{CO}_{2}$. In $\mathrm{CO}_{2}$-poor environments, almost every sample showed no reflexes in XRD referred to as hydrotalcite-like. Only an endothermic process in specific temperature ranges in STA was observed for which possibly rather a delayed degradation of betaine sorbed on the nanomaterials could be considered or a combination of both. However, this has to be studied more in detail to enable a clear statement about the reaction products built depending on the present nanomaterials and environment (i.e. media, present ions etc.). Finally, it was assumed that C-S-H formation could be affected by the surfactant $[23,24,26]$.

\section{Influence of cocamidopropyl betaine on the formation and carbonation of portlandite}

To investigate the influence of the surfactant cocamidopropyl betaine on the pore structure in more detail, crystallization and carbonation of calcium hydroxide with and without betaine were observed [23,27]. Here, diffusion and precipitation synthesis were used and investigations regarding the influence of betaine on the morphology of synthesized $\mathrm{CH}$ carried out. It was found that without betaine the typical oblong hexagonal crystals of $\mathrm{CH}$ were formed but a significant difference in morphology and surface in presence of betaine occurred. Smaller crystals with a rough and rugged surface instead of a smooth surface can be seen. These crystals were strongly branched and showed many growth centers. It was assumed that one main influence of betaine on $\mathrm{CH}$ is based on the sorption of molecules on the crystal planes also observed in [28]. At higher concentrations betaine strongly affects the morphology of $\mathrm{CH}$ [27]. After certain consumption of betaine during $\mathrm{CH}$ formation, very small typical hexagonal plates can be observed on the crystal surface (Fig. 6).

In case of precipitation synthesis the particle sizes were decreased by increasing surfactant concentration. The highest betaine concentration additionally led to hollowed crystals which were assumed as the dissolution of metastable structures formed due to the influence of betaine.

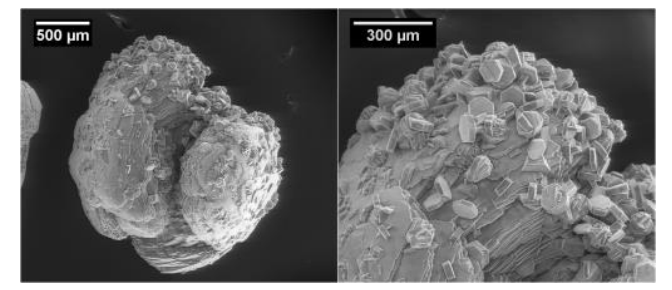

Fig. 6. SEM images of $\mathrm{CH}$ crystals formed in betaine solution during diffusion synthesis.

Investigating the influence on carbonation showed that formed calcium carbonate was smaller in particle size in the presence of betaine. Freely available surfactant molecules affected carbonation which resulted from in-situ $\mathrm{XRD}$ of $\mathrm{CH}$ liquid surfaces and slurries with and without betaine. Hereby, it was shown that the crystallization of calcite was inhibited at $\mathrm{CH}$ liquid surfaces and calcite 
formation in the slurries was slowed down at the beginning $[23,27]$.

\section{Conclusion}

Three-phase-foams offer several advantages for different applications. Inorganic foams with wet densities of less than $150 \mathrm{~kg} / \mathrm{m}^{3}$ were produced. The incorporation of nanotubes in the foam system can increase the stability of three-phase-foams. A combination of this further stabilization or nanoreinforcement, respectively, with hardening process based on pozzolanic reaction could lead to inorganic foams which are low cost in preparation. The developed inorganic foams could afford several application areas such as insulation after prospective final improvement (e.g. autoclaving after treatment or implementation in other binders etc.). To conclude, threephase-foams provide many possibilities for the combination with other surface active agents, nanomaterials and binders to improve the strength and adaption to the respective requirements for different applications.

Moreover, three-phase-foams with environmental friendly long-chain surfactants were successfully prepared and enable the production of foam concrete. Resulting foam concretes provide improved mechanical properties and showed a specific pore structure. Applied UHPC formulation further enhance mechanical as well as microstructural properties and resulting phase composition. In addition, nanotubes in three-phase-foams were further integrated to adapt certain properties of those and could also provide strengthening reaction products by seeding or pozzolanic reaction, respectively.

Finally, a new way to incorporate pozzolans as well as nanotubes for reinforcement in both foam concrete and UHPC foam concrete to achieve a strengthening and improved performance was developed. Overall, the study showed that the production of foam concretes on the basis of three-phase-foams offers great potential for technical application due to the demonstrable improvement of the material properties.

\section{Acknowledgements}

The authors express their thanks to the workers of the Institute for Building and Materials Chemistry at the University of Siegen, especially Dr. M. Schauerte, Dr. C. Pritzel, Dipl.-Chem. T. Müller and Dr. T. Kowald for their support and inspiring discussions.

\section{References}

1. Krämer, C.; Schauerte, M.; Kowald, T.; Trettin, R.H.F. Mater. Charact., 2015, 102, 173-179.

DOI: $10.1016 /$ j.matchar.2015.03.004

2. Dhir, R:K.; Newlands, M.D.; McCarthy, A. (Eds.); Use of Foamed Concrete in Construction; ThomasTelford: London, 2005. ISBN: $\underline{0727734067}$

3. Chandra, S.; Berntsson, L. Historical background of LWAC. In Lightweight Aggregate Concrete: Science, Technology and Applications; Noyes Publications + William Andrew Publishing: Norwich, 2002, pp. 5-19. ISBN: 0815514867

4. DIN 1045-1, Concrete, Reinforced and Prestressed Concrete Structures - Part 1: Design and Construction, 2008.

5. Faust, T. Allgemeines. In Leichtbeton im konstruktiven Ingenieurbau; Ernst\&Sohn: Berlin, 2003, p. 2.

ISBN: 978-3-433-01613-8
6. Jones, M. R.; Zheng, L.; Ozlutas, K. Mag Concrete Res, 2015, 68 (11), 542-549.

DOI: $10.1680 /$ macr. 15.00097

7. Narayanan, N.; Ramamurthy, K. Cem Con Comp, 2000, 22, pp. 321-329.

DOI: $10.1016 / \mathrm{S} 0958-9465(00) 00016-0$

8. Just, A.; Middendorf, B. Mater. Charact., 2009, 60 (7), pp.741-748.

DOI: $10.1016 /$ j.matchar.2008.12.011

9. Schauerte, M.; Trettin R. $18^{\text {th }}$ Ibausil, Weimar, 2-0066-2-0072, 2012.

ISBN: 978-3-00-034075-8

10. Richard, P.; Cheyrezy, M.H. ACI Special Publications, 1994, 144, 507-518.

11. Richard, P.; Cheyrezy, M.H. Cem. Con. Res., 1995, 25(7), 15011511.

DOI: $10.1016 / 0008-8846(95) 00144-2$

12. Dinger, D.R. Dense Packing. In Particle Calculations for Ceramists; Morris Publishing: United States, 2001, pp. 89-102.

ISBN: $0-9715696-0-6$

13. Krämer, C.; Schauerte, M.; Kowald, T.; Trettin, R. $14^{\text {th }}$ International Congress on the Chemistry of Cement, Abstract Book II, p. 377, 2015.

14. Keriene, J.; Kligys, M.; Laukaitas, A.; Yakolev, G.; Spokauskas, A.; Aleknevicius, M. Constr. Build. Mater, 2013, 49, 527-535. DOI: $10.1016 / j$.conbuildmat.201308044

15. Yakolev, G.; Pervushin, G.; Maeva, I.; Keriene, J.; Pudov, I.; Shaybadullina, A.; Buryanov, A.; Korzhenko, A.; Senkov, S. Procedia Eng., 2013, 57, 407-413. DOI: $10.1016 /$ j.proeng.2013.04.053

16. Yakolev, G.; Keriene, J.; Gailius, A.; Girniene, I. Mater. Sci., 2006, 12(2), 147-151.

ISSN: $\underline{1392-1320}$

17. Li, G.; Y, Wang, P.M., Zhao, X. Carbon, 2005, 43(6), 1239-1245. DOI: $10.1016 /$ j.carbon.2004.12.017

18. Kowald, T.; Trettin, R. Nanotechnology in Construction 3, Springer International Publishing, pp.261-266, 2009.

DOI: $\underline{10.1007 / 978-3-642-00980-8 \quad 34}$

19. Gonzenbach, U. T.; Studart, A. R.; Tervoort, E.; Gauckler, L. J. Angew. Chem. Int. Ed., 2006, 45(21), 3526-3530. DOI: $\underline{10.1002 / \text { anie. } 200503676}$

20. Studart, A. R.; Gonzenbach, U. T.; Tervoort, E.; Gauckler, L. J. J. Am. Ceram. Soc., 2006, 89(6), 1771-1789. DOI: $10.1111 / \mathrm{j} .1551-2916.2006 .01044$

21. Krämer, C.; Kowald, T.; Trettin, R. Nanotechnology in Construction 5, Springer International Publishing, pp.235-239, 2015. DOI: $10.1007 / 978-3-319-17088-6 \quad 57$

22. Krämer, C.; Zhangxiang, D.; Trettin, R. 4th International Symposium on UHPC and High Performance Construction Materials, Vol. 27, pp.15-16, 2016.

ISBN: 978-3-7376-0094-1

23. Krämer, C.; Schauerte, M.; Müller, T.; Gebhard, S.; Trettin, R.H.F. Constr. Build. Mater., 2016, 131, 746-757. DOI: $10.1016 / \mathrm{j}$. conbuildmat.2016.11.027

24. Krämer, C.; Kowald, T.L.; Trettin, R.H.F. Cem. Con. Comp., 2015, $62,44-51$.

DOI: $10.1016 /$ j.cemconcomp.2015.06002

25. Krämer, C.; Kowald, T.L.; Butters, V.; Trettin, R.H.F. J. Mater. Sci., 2016, 8, 3715-3723.

DOI: $10.1007 / \mathrm{s} 10853-015-9689-2$

26. Krämer, C.; Azubike, O.M.; Trettin, R.H.F. Cem. Con. Comp., 2016, 73, 174-184.

DOI: $10.1016 /$ j.cemconcomp.2016.07.012

27. Krämer, C.; Müller, T.; Pritzel, C.; Kowald, T.L.; Bornemann, R.; Trettin, R.H.F. Constr. Build. Mater., 2016, under review.

28. Arnld, $\mathrm{M}$. $\mathrm{PhD}$ thesis, 2004. Available online at http://dokumentix.ub.uni siegen.de/opus/volltexte/2006/74

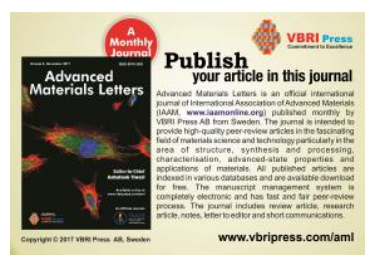

